\title{
Mathematical modeling for a multiproduct manufacturing system featuring postponement, external suppliers, overtime, and scrap
}

\author{
Yuan-Shyi P. Chiu ${ }^{a}$, Jian-Hua Lian ${ }^{a}$, Victoria Chiu ${ }^{b}$, Yunsen Wang ${ }^{c}$ and Hsiao-Chun Wu ${ }^{d^{*}}$
}

${ }^{a}$ Department of Industrial Engineering \& Management, Chaoyang University of Technology, Taiwan

${ }^{b}$ Department of Accounting, Finance \& Law, State University of New York, Oswego, NY, USA

${ }^{c}$ Department of Accounting \& Finance, Feliciano School of Business, Montclair State University, Montclair, New Jersey, USA

${ }^{d}$ Department of Business Administration, Chaoyang University of Technology, Taiwan

\begin{tabular}{l}
\hline C H R O N I C L E \\
\hline Article history: \\
Received August 202021 \\
Received in Revised Format \\
August 28 2021 \\
Accepted September 282021 \\
Available online \\
September, 28 2021 \\
\hline Keywords: \\
Mathematical modelling \\
Multiproduct fabrication \\
External supplier \\
Overtime \\
Scrap \\
Postponement \\
Rotation cycle \\
Batch production
\end{tabular}

Batch production
Received August 202021

Received in Revised Format

August 282021

Available online

Mathematical modelling

Multiproduct fabricatio

Overtime

Scrap

\section{A B S T R A C T}

\begin{abstract}
Manufacturing firms operating in today's competitive global markets must continuously find the appropriate manufacturing scheme and strategies to effectively meet customer needs for various types of quality of merchandise under the constraints of short order lead-time and limited in-house capacity. Inspired by the offering of a decision-making model to aid smooth manufacturers' operations, this study builds an analytical model to expose the influence of the outsourcing of common parts, postponement policies, overtime options, and random scrapped items on the optimal replenishment decision and various crucial system performance indices of the multiproduct problem. A two-stage fabrication scheme is presented to handle the products' commonality and the uptime-reduced strategies to satisfy the short amount of time before the due dates of customers' orders. A screening process helps identify and remove faulty items to ensure the finished lot's anticipated quality. Mathematical derivation assists us in finding the manufacturing relevant total cost function. The differential calculus helps optimize the cost function and determine the optimal stock-replenishing rotation cycle policy. Lastly, a simulated numerical illustration helps validate our research result's applicability and demonstrate the model's capability to disclose the crucial managerial insights and facilitate manufacturing-relevant decision making.
\end{abstract}

\section{Introduction}

This study builds an analytical model to explore a multiproduct fabrication problem featuring postponement, external suppliers, overtime, and scrap. We aim to help manufacturers smoothen their fabrication planning and operations so that they could effectively meet today's customer needs for various types of quality merchandise under short-order lead-time and limited in-house capacity constraints. Multiproduct' commonality feature inspires production managers to design alternative manufacturing schemes such as the postponement option to gain potential savings in uptime or total fabrication-relevant costs. Aviv and Federgruen (2001) explored the benefits of a postponement model featuring dependent and unknown-distribution random demand. Accordingly, their model needed to continuously revise the estimation of demand-distribution- related parameters under a Bayesian framework to find the near-optimal ordering policies for various ordering costs. Ceryan et al. (2012) examined the admission control and fabrication decisions of a two-stage assembly-production system that must meet end-product' and intermediate parts' demands. The admission controls decisions related to acceptance or rejection of orders based on current stock-level and whether they are profitable. The researchers attempted to use a simple heuristic to test different example problems for exploring the optimal replenishment policy and its performance. Cerdá et al. (2020) studied the short-term production schedule for fabricating semifinished and final products using separate sequential batch processes in a make-to-order environment. The researchers built an efficient mixed-integer linear programming model based on the

* Corresponding author

E-mail: sc524@gm.cyut.edu.tw (H-C.Wu)

2022 Growing Science Ltd. doi: $10.5267 /$ j.ijiec. 2021.9 .003 
processes precedence relationship to decide the lot sizes and the synchronized fabrication schedules of the semifinished and final products. Recent works (Chiu et al., 2020; Nogueira, et al., 2020; Sharma and Rai, 2021) studied the influence of postponement strategies on diverse multiproduct manufacturing systems' planning, scheduling, and operations.

Meeting customer's anticipated merchandise quality is one of the primary competitive strategies of present-day manufacturers. The screening process helps manufacturers identify and remove inevitable faulty items produced to ensure the finished lot's quality. Kenne et al. (2003) explored the optimal fabrication control for a multiproduct multi-machine production system subject to machine failures. Their approach included a corrective maintenance plan on a failed machine to improve the system's productivity. In their model, both the fabrication and machine-repairing rates are the decision variables that affect the system's capacity and stock-level. The researchers used numerical methods and a computational algorithm to solve the optimal fabrication control problem that minimized the system's repair activities and total system costs. Finally, the researchers extended and discussed more a complex system. Sarkar and Moon (2011) studied a stochastic economic production quantity-based system featuring Weibull-distributed imperfect fabrication process, rework, shortages, and inflation. The researchers considered uniform-rectangular-distributed and general-distributed demands and developed a profit function for their model. By using computational experiments and graphical demonstration, they explored and discussed their probability model's optimality. Kundu et al. (2019) examined a seasonal multiproduct batch manufacturing system featuring time-sensitive demand and variable fabrication and defective rates. The remanufacturing of faulty items initiates with extra cost, right after these items are produced and identified. The researchers formulated a profit-maximization model with space and investment constraints to explore their proposed batch manufacturing problem. The researchers further incorporated fuzzy constraints into their model and used numerical experiments with sensitivity analyses to demonstrate the model's performance. Recent works (Alves et al., 2019; Belogusev and Egorov, 2019; Pinto et al., 2020; Salehi Amiri et al., 2020; Sarkar and Chung, 2020) explored the influence of imperfect manufacturing processes on diverse fabrication planning, controlling, and management.

Meeting the growing trend of the short amount of time before customer orders' due dates and coping with limited in-house capacity, present-day's fabrication planners always implement effective ways such as subcontracting or overtime shifts to reduce production uptime. Insinga and Werle (2000) examined the impact of aggressive outsourcing policies on diverse business operations. The researchers identified and discussed the outsourcing-relevant dependencies, their potential pitfalls, and corresponding coping actions to guide managerial decision making on linking outsourcing to corporate strategy. Boctor and Poulin (2007) proposed composite heuristics to explore a dynamic-demand economic lot-sizing and scheduling problem featuring multi-product, multi-stage, and limited capacity. The researchers first found each product's feasible solution in each period. Then, they used a recursive improving procedure to derive a more economical and capacity-feasible solution. The researchers further extended their work by considering the overtime options in the improving stage to increase capacity and save the total system costs. They offered numerical illustrations to validate their heuristics and solution procedures and show their performance. Westphal and Sohal (2013) proposed and evaluated outsourcing models' classification to help practitioners choose the appropriate outsourcing model for their corporation. The researchers also identified and discussed the limitations of outsourcing decision processes presented in the existing literature. Abdel-Aal (2019) utilized a mixed-integer linear programming approach to study a multi-period multi-product lot-sizing problem featuring uncertain demands/budgets, setup times, limited capacity, overtime and permitted backlogging. The research started with considering the model of deterministic demands and then extended to the stochastic demands ones. The author provided numerical experiments to validate their results. Recent works (Fontinha et al., 2019; Pasupa and Suzuki, 2019; Soriano et al., 2020; Abdul Halim et al., 2021; Chiu et al., 2021; Keyvanshokooh et al., 2021) investigated the impact of different subcontracting and overtime policies on different fabrication-inventory systems, supply chains, and business operating controls. Fewer past works specifically focused on investigating the impact of external suppliers, postponement, overtime, and scrap on the multiproduct fabrication problem; we aim to bridge this gap.

\section{Problem and Methodology}

\subsection{Nomenclature and problem description}

This study employs a two-stage mathematical modeling approach to solve the rotation cycle length for a single-machine multiproduct fabrication problem featuring postponement, external suppliers for common parts, overtime option for producing end products, and random existence of scraps. The notation used in our model is displayed in Appendix A. The following is the description and assumption of our two-stage mathematical model: assuming the common intermediate part exists in a twostage multiproduct batch fabrication plan, where the annual demand $\lambda_{i}$ of these $L$ finished products $(i=1,2, \ldots, L)$ must be satisfied. We use a delayed product differentiation (postponement) strategy to gain the potential benefits of rapid order response time and total cost savings. That is, stage one of the batch plan manufactures all necessary common parts, and stage2 fabricates all end products. This study assumes a constant completion rate $\gamma$ for common part's as compared to its finished product, and both production rates $P_{1,0}$ and $P_{1, i}$ depending on $\gamma$. For instance, if $\gamma=0.5$, then both $P_{1,0}$ and $P_{1, i}$ are twice as much as their ordinary rates in a single-stage model. Furthermore, to expedite the batch process, we consider a partial outsourcing portion $\pi_{0}$ of common parts in stage- 1 . An overtime option with additional proportion $\alpha_{1, i}$ for fabricating product $i$ in stage two. The impact of these process accelerated strategies on the relevant cost and output-rate parameters as exhibited 
below (refer to Nomenclature for details):

$$
\begin{aligned}
& P_{\mathrm{T} 1, i}=P_{1, i}\left(1+\alpha_{1, i}\right) \\
& K_{\mathrm{T}, i}=K_{i}\left(1+\alpha_{2, i}\right) \\
& C_{\mathrm{T}, i}=C_{i}\left(1+\alpha_{3, i}\right) \\
& K_{\pi 0}=K_{0}\left(1+\beta_{1,0}\right) \\
& C_{\pi 0}=C_{0}\left(1+\beta_{2,0}\right)
\end{aligned}
$$

Furthermore, the inevitable random scrap rates $x_{0}$ and $x_{i}$ exist in both production stages. The faulty items are screened and removed. Fig. 1 exhibits our proposed multiproduct fabrication model's stock status featuring postponement, external suppliers, overtime, and scrap. It specifies the common part's stocks stack to $H_{1,0}$ when $t_{1,0}$ ends; meantime, the receipt of outsourced items brings its level to $H_{2,0}$ before the starting time of stage two. Then, in stage two, the stocks of end product $i$ stack to $H_{1, i}$, when the uptime $t_{1, i}$ completes, it follows that the stock level of product $i$ depletes under a continuous issuing discipline (see Fig. 1).

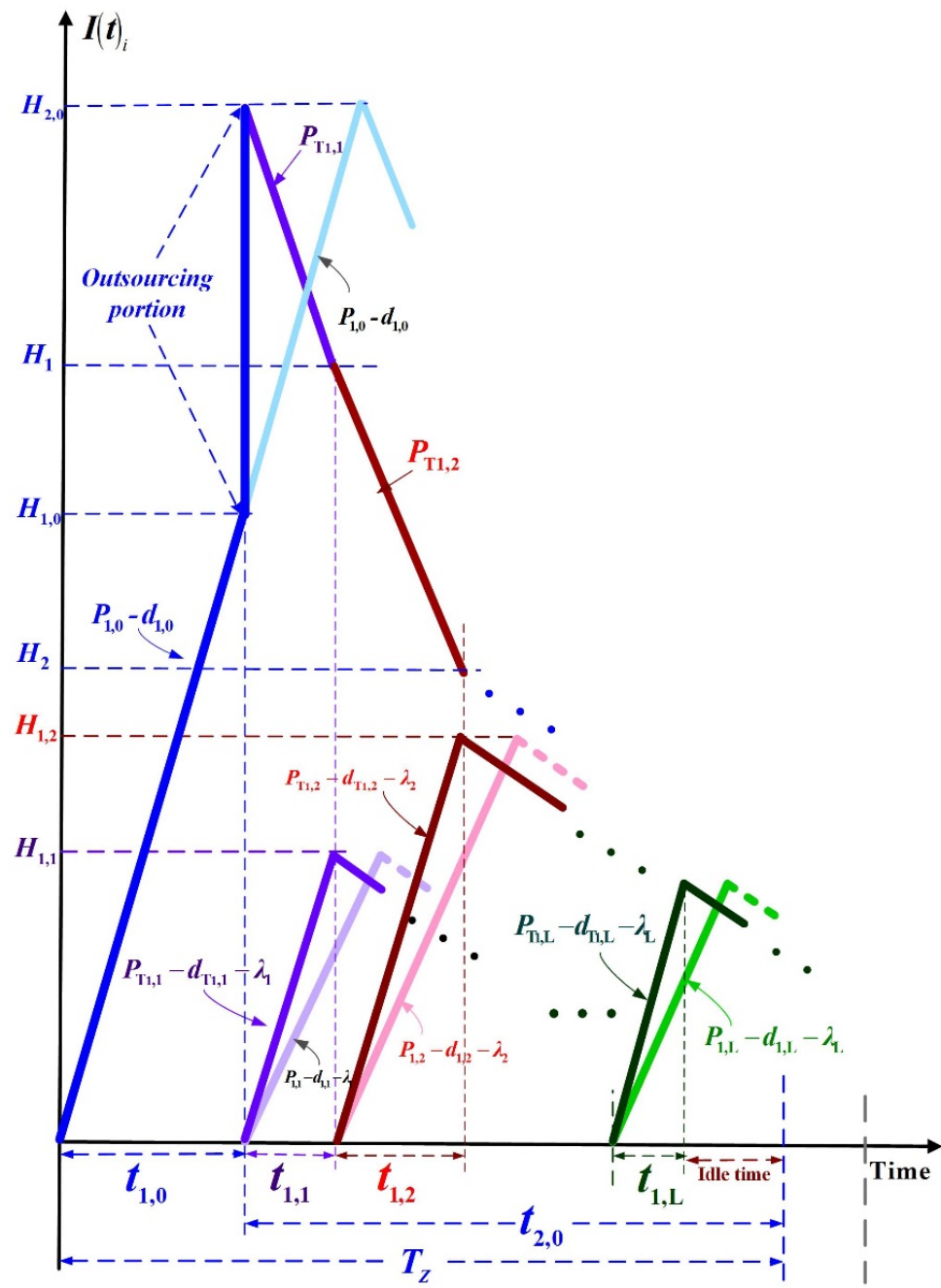

Fig. 1. Stock level of our proposed multiproduct fabrication model featuring postponement, external suppliers, overtime, and scrap, compared to a model without external suppliers nor overtime

Fig. 2 shows the status of scraps of the proposed multiproduct model. It indicates the scrapped common parts pile up to $\left(d_{1,0}\right.$ $\left.t_{1,0}\right)$ when $t_{1,0}$ completes, and it starts to deplete to zero in $t_{2,0}$. In stage two, similar conditions happen for the scrapped end products. Because our model doesn't allow shortages, hence, both of the following $\left(P_{\mathrm{T} 1, i}-d_{\mathrm{T} 1, i}-\lambda_{i}\right)>0$ and $\left(P_{1,0}-d_{1,0}\right)>0$ must hold. 


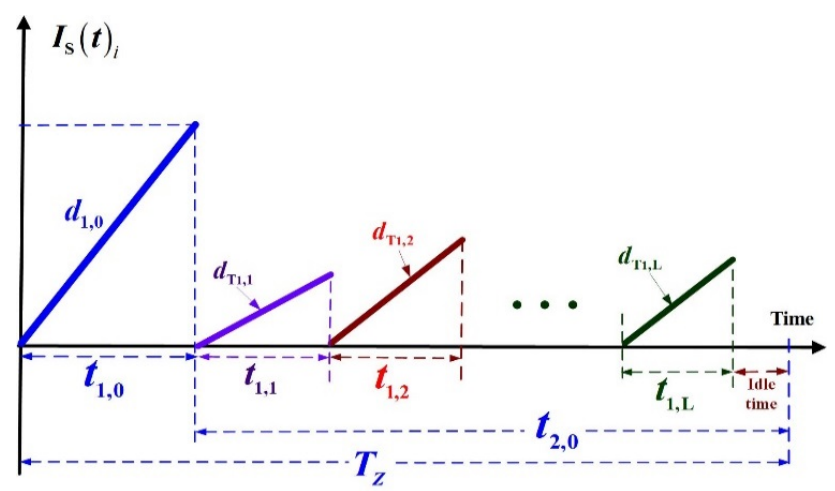

Fig. 2. Status of scraps of our multiproduct fabrication model

\subsection{Formulations, derivation, and optimization}

Fig. 1 points out that starting stage two, the needed common parts for manufacturing each end product $i$ start to deplete $Q_{i}$ from $H_{2,0}$ to $H_{i}$. Fig. 3 exhibits a clear picture of common parts' level in the second stage, and Eqs. (6) to (8) display its details.

$$
\begin{aligned}
& H_{1}=H_{2,0}-Q_{1} \\
& H_{i}=H_{(i-1)}-Q_{i}, \text { for } i=2,3, \ldots, L \\
& H_{L}=H_{(L-1)}-Q_{L}=0
\end{aligned}
$$

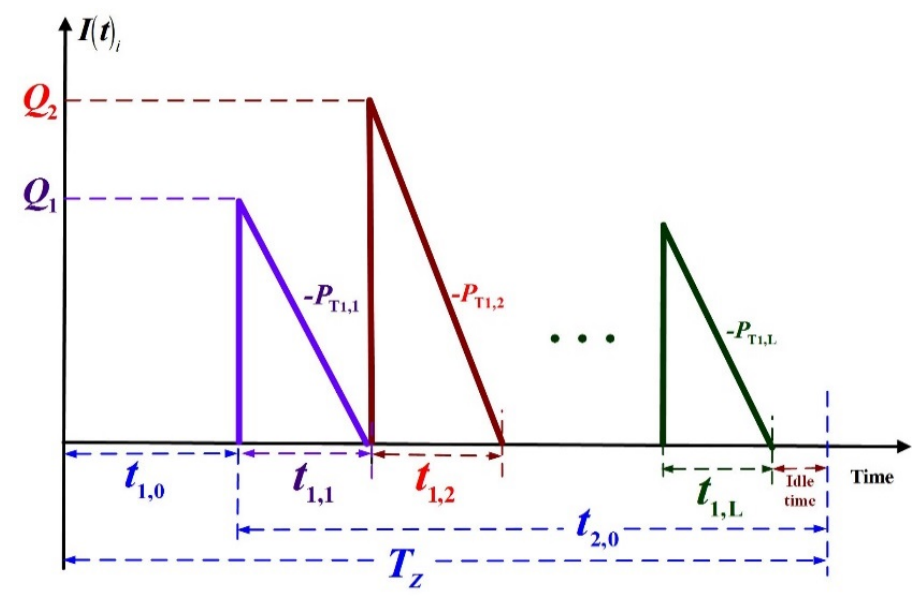

Fig. 3. Status of common parts of our multiproduct fabrication model

The following equations can be straightforwardly observed according to Fig. 1 to Fig. 3, and the problem statement:

$$
\begin{aligned}
& T_{Z}=t_{1, i}+t_{2, i}, \text { where } i=0,1,2, \ldots, L \\
& Q_{i}=\frac{\lambda_{i} T_{Z}}{1-x_{i}} \\
& H_{1, i}=t_{1, i}\left(P_{T 1, i}-d_{T 1, i}-\lambda_{i}\right) \\
& t_{1, i}=\frac{Q_{i}}{P_{T 1, i}} \\
& t_{2, i}=\frac{H_{1, i}}{\lambda_{i}}
\end{aligned}
$$

According to the total required lot sizes of end product $i$ (as displayed in equation (10)), the following are the total common parts required:

$$
H_{2,0}=\sum_{i=1}^{L} Q_{i}=\sum_{i=1}^{L} \frac{\lambda_{i} T_{Z}}{1-x_{i}}
$$


From Fig. 1 to Fig. 3, we can also straightforwardly observe the following equations:

$$
\begin{aligned}
& \lambda_{0}=\frac{\sum_{i=1}^{L} Q_{i}}{T_{Z}} \\
& H_{1,0}=\left(1-\pi_{0}\right)\left(\sum_{i=1}^{L} Q_{i}\right)=H_{2,0}\left(1-\pi_{0}\right) \\
& Q_{0}=\frac{H_{1,0}}{1-x_{0}} \\
& t_{1,0}=\frac{Q_{0}}{P_{1,0}} \\
& H_{1,0}=\left(P_{1,0}-d_{1,0}\right) t_{1,0}
\end{aligned}
$$

$T C\left(T_{\mathrm{Z}}\right)$ consists of the expenses incurred in stage one's variable and setup costs for outsourcing and in-house manufacturing, stockholding of scrap and safety items, and disposal costs; in stage two's sum of setup cost, variable cost, holding cost of scrap and safety items, and disposal cost. Therefore, we have the following $T C\left(T_{\mathrm{z}}\right)$ :

$$
\begin{aligned}
T C\left(T_{Z}\right) & =K_{\pi 0}+C_{\pi 0}\left(\sum_{i=1}^{L} Q_{i}\right) \pi_{0}+C_{0} Q_{0}+K_{0}+C_{S, 0}\left(Q_{0} x_{0}\right)+h_{4,0}\left(x_{0} Q_{0}\right) T_{Z} \\
& +h_{1,0}\left[\frac{H_{1,0} t_{1,0}}{2}+\frac{d_{1,0} t_{1,0}}{2}\left(t_{1,0}\right)+\sum_{i=1}^{L}\left[\frac{Q_{i}}{2}\left(t_{1, i}\right)+H_{i}\left(t_{1, i}\right)\right]\right] \\
& +\sum_{i=1}^{L}\left\{K_{\mathrm{T}, i}+Q_{i} C_{\mathrm{T}, i}+\left(Q_{i} x_{i}\right) C_{S, i}+h_{1, i}\left[\frac{d_{T 1, i} t_{1, i}}{2}\left(t_{1, i}\right)+\frac{H_{1, i} t_{2, i}}{2}+\frac{H_{1, i} t_{1, i}}{2}\right]+h_{4, i}\left(x_{i} Q_{i}\right) T_{Z}\right\}
\end{aligned}
$$

Apply the expected $E\left[x_{i}\right]$ (for $\left.i=0,1,2, \ldots, L\right)$ to deal with the random scrap, replace Eqs. (1) to (19) in Eq. (20), and finall $\mathrm{y}$, applying $E\left[T C\left(T_{\mathrm{Z}}\right)\right] / E\left[T_{\mathrm{Z}}\right]$, we obtain the following the expected total fabrication-inventory expense per unit time $E[T C U$ $\left.\left(T_{\mathrm{Z}}\right)\right]$ :

$$
\begin{aligned}
& E\left[T C U\left(T_{Z}\right)\right]=\left\{\begin{array}{l}
\frac{K_{0}\left(1+\beta_{1,0}\right)}{T_{Z}}+C_{0} \pi_{0}\left(1+\beta_{2,0}\right) \lambda_{0}+\frac{K_{0}}{T_{Z}}+\frac{C_{0} \lambda_{0}\left(1-\pi_{0}\right)}{1-E\left[x_{0}\right]}+\frac{h_{4,0} \lambda_{0} E\left[x_{0}\right]\left(1-\pi_{0}\right)}{1-E\left[x_{0}\right]} T_{Z} \\
+\frac{C_{S, 0} E\left[x_{0}\right]\left(1-\pi_{0}\right) \lambda_{0}}{1-E\left[x_{0}\right]}+\frac{h_{1,0}\left(1-\pi_{0}\right)^{2} \lambda_{0}{ }^{2} T_{Z}}{2 P_{1,0}\left(1-E\left[x_{0}\right]\right)^{2}}+h_{1,0} \sum_{i=1}^{L}\left\{\frac{\lambda_{i}^{2} T_{Z}}{2\left(1-E\left[x_{i}\right]\right)^{2}\left[\left(1+\alpha_{1, i}\right) P_{1, i}\right]}\right] \\
+h_{1,0}\left\{\sum_{i=1}^{L}\left[\frac{\lambda_{i} T_{Z}}{\left(1-E\left[x_{i}\right]\right)}\right]-\sum_{j=1}^{i}\left[\frac{\lambda_{j} T_{Z}}{\left(1-E\left[x_{j}\right]\right)}\right]\right\} \cdot \sum_{i=1}^{L}\left\{\left[\frac{\lambda_{i}}{\left(1-E\left[x_{i}\right]\right)}\right] \frac{1}{\left[\left(1+\alpha_{1, i}\right) P_{1, i}\right]}\right]
\end{array}\right\} \\
& +\sum_{i=1}^{L}\left\{\begin{array}{l}
{\left[\frac{C_{i} \lambda_{i}}{1-E\left[x_{i}\right]}\right]\left(1+\alpha_{3, i}\right)+\frac{K_{i}\left(1+\alpha_{2, i}\right)}{T_{Z}}+\left[\frac{C_{S, i} \lambda_{i} E\left[x_{i}\right]}{1-E\left[x_{i}\right]}\right]} \\
+\frac{h_{4, i} E\left[x_{i}\right] \lambda_{i}}{\left(1-E\left[x_{i}\right]\right)} T_{Z}+\frac{h_{1, i} \lambda_{i}^{2}}{2\left(1-E\left[x_{i}\right]\right)^{2}}\left[\frac{\left(1-E\left[x_{i}\right]\right)^{2}}{\lambda_{i}}-\frac{1-2 E\left[x_{i}\right]}{\left(1+\alpha_{1, i}\right) P_{1, i}}\right] T_{Z}
\end{array}\right\}
\end{aligned}
$$

Let $E_{00}, E_{10}, E_{0 j}, E_{0 i}, E_{1 i}, E_{2 i}$, and $E_{3 i}$ represent the following:

$$
\begin{aligned}
& E_{00}=\frac{1}{\left(1-E\left[x_{0}\right]\right)} ; E_{10}=\frac{E\left[x_{0}\right]}{\left(1-E\left[x_{0}\right]\right)} ; E_{0 j}=\frac{1}{\left(1-E\left[x_{j}\right]\right)} \\
& E_{0 i}=\frac{1}{\left(1-E\left[x_{i}\right]\right)} ; E_{1 i}=\frac{E\left[x_{i}\right]}{\left(1-E\left[x_{i}\right]\right)} ; E_{2 i}=\frac{1}{\left[\left(1+\alpha_{1, i}\right) P_{1, i}\right]} ; E_{3 i}=\left[\frac{\left(1-E\left[x_{i}\right]\right)^{2}}{\lambda_{i}}-\frac{1-2 E\left[x_{i}\right]}{\left(1+\alpha_{1, i}\right) P_{1, i}}\right]
\end{aligned}
$$


Substitute Eqs. (21) and (22) in Eq. (20), we derive $E\left[T C U\left(T_{\mathrm{Z}}\right)\right]$ as follows:

$$
\begin{aligned}
E\left[T C U\left(T_{Z}\right)\right]=\left\{\begin{array}{l}
\frac{K_{0}\left(1+\beta_{1,0}\right)}{T_{Z}}+C_{0}\left(1+\beta_{2,0}\right) \pi_{0} \lambda_{0}+C_{0} \lambda_{0} E_{00}\left(1-\pi_{0}\right)+\frac{K_{0}}{T_{Z}}+h_{4,0} \lambda_{0} E_{10}\left(1-\pi_{0}\right) T_{Z} \\
+C_{S, 0} E_{10}\left(1-\pi_{0}\right) \lambda_{0}+\frac{h_{1,0}\left(E_{00}\right)^{2} \lambda_{0}^{2}}{2 P_{1,0}}\left(1-\pi_{0}\right)^{2} T_{Z}+h_{1,0} \sum_{i=1}^{L}\left\{\frac{\left(E_{0 i}\right)^{2} \lambda_{i}^{2} T_{Z}}{2 P_{1, i}\left(1+\alpha_{1, i}\right)}\right\} \\
+h_{1,0}\left\{\sum_{i=1}^{L}\left[\lambda_{i} E_{0 i} T_{Z}\right]-\sum_{j=1}^{i}\left[\lambda_{j} E_{0 j}\right] T_{Z}\right\} \cdot \sum_{i=1}^{L}\left(\lambda_{i} E_{0 i} E_{2 i}\right)
\end{array}\right\} \\
+\sum_{i=1}^{L}\left\{C_{i} \lambda_{i}\left(1+\alpha_{3, i}\right) E_{0 i}+\frac{K_{i}\left(1+\alpha_{2, i}\right)}{T_{Z}}+C_{S, i} E_{1 i} \lambda_{i}+\frac{h_{1, i} E_{3 i}\left(\lambda_{i} E_{0 i}\right)^{2}}{2} T_{Z}+h_{4, i} E_{1 i} \lambda_{i} T_{Z}\right\}
\end{aligned}
$$

To determine $T_{\mathrm{Z}}{ }^{*}$, we apply the first- and second-derivative to $E\left[T C U\left(T_{\mathrm{Z}}\right)\right]$ and result as follows:

$$
\begin{aligned}
& \begin{array}{l}
\frac{d E\left[T C U\left(T_{Z}\right)\right]}{d\left(T_{Z}\right)}=\left\{\begin{array}{l}
-\frac{K_{0}}{T_{Z}{ }^{2}}-\frac{\left(1+\beta_{1,0}\right) K_{0}}{T_{Z}{ }^{2}}+h_{1,0}\left(1-\pi_{0}\right)^{2} \frac{\lambda_{0}{ }^{2}}{2 P_{1,0}}\left(E_{00}\right)^{2}+h_{4,0} \lambda_{0}\left(1-\pi_{0}\right) E_{10} \\
+h_{1,0}\left[\sum_{i=1}^{L}\left(\lambda_{i} E_{0 i}\right)-\sum_{j=1}^{i}\left(\lambda_{j} E_{0 j}\right)\right] \cdot \sum_{i=1}^{L}\left(\lambda_{i} E_{0 i} E_{2 i}\right)+h_{1,0} \sum_{i=1}^{L}\left\{\frac{\left(E_{0 i}\right)^{2} \lambda_{i}^{2}}{2\left[P_{1, i}\left(1+\alpha_{1, i}\right)\right]}\right\}
\end{array}\right\} \\
+\sum_{i=1}^{L}\left\{+h_{1, i} \frac{E_{3 i}\left(\lambda_{i} E_{0 i}\right)^{2}}{2}-\frac{K_{i}\left(1+\alpha_{2, i}\right)}{T_{Z}{ }^{2}}+h_{4, i} \lambda_{i} E_{1 i}\right\}
\end{array} \\
& \begin{aligned}
\frac{d^{2} E\left[T C U\left(T_{Z}\right)\right]}{d\left(T_{Z}\right)^{2}}= & \frac{2 K_{0}}{T_{Z}{ }^{3}}+\frac{2 K_{0}\left(1+\beta_{1,0}\right)}{T_{Z}{ }^{3}}+\sum_{i=1}^{L} \frac{2 K_{i}\left(1+\alpha_{2, i}\right)}{T_{Z}{ }^{3}}>0
\end{aligned}
\end{aligned}
$$

In Eq. (26), because $\alpha_{2, i}, T_{\mathrm{Z}}, \beta_{1,0}, K_{i}$, and $K_{0}$ are all positive; so, $E\left[T C U\left(T_{\mathrm{Z}}\right)\right]$ is convex. Let the first derivative of $E\left[T C U\left(T_{\mathrm{Z}}\right)\right]$ $=0$ (i.e., Eq. $(25)=0$ ), one derives the optimal $T_{\mathrm{Z}}$.

$$
T_{Z}^{*}=\sqrt{\frac{2\left\{K_{0}\left(2+\beta_{1,0}\right)+\sum_{i=1}^{L}\left[K_{i}\left(1+\alpha_{2, i}\right)\right]\right\}}{2 h_{1,0}\left[\sum_{i=1}^{L}\left(\lambda_{i} E_{0 i}\right)-\sum_{j=1}^{i}\left(\lambda_{j} E_{0 j}\right)\right] \cdot \sum_{i=1}^{L}\left(\lambda_{i} E_{0 i} E_{2 i}\right)+h_{1,0} \sum_{i=1}^{L}\left[\frac{\left(E_{0 i}\right)^{2} \lambda_{i}^{2}}{P_{1, i}\left(1+\alpha_{1, i}\right)}\right]+2 h_{4,0} \lambda_{0}\left(E_{10}\right)\left(1-\pi_{0}\right)}}
$$

\section{Numerical Example}

Assume the following parameters' values (as displayed in Tables 1 and 2) are for a batch manufacturing plan of a multiproduct replenishing problem with postponement, random scrap, overtime strategy for end products manufacturing, and external suppliers for common parts. In contrast, the values of parameters assumed for the same problem with a single-stage scheme are exhibited in Table B-1 in Appendix B.

\begin{tabular}{|c|c|c|c|c|c|c|c|c|c|c|c|c|}
\hline Product $i$ & $\alpha_{1, i}$ & $P_{1, i}$ & $\lambda_{i}$ & $\alpha_{2, i}$ & $C_{i}$ & $\alpha_{3, i}$ & $C_{\mathrm{S}, i}$ & $K_{i}$ & $x_{i}$ & $\overline{i_{i}}$ & $h_{4, i}$ & $h_{1, i}$ \\
\hline 1 & 0.5 & 112258 & 3000 & 0.1 & $\$ 40$ & 0.25 & $\$ 10$ & $\$ 8500$ & $2.5 \%$ & 0.2 & $\$ 16$ & $\$ 16$ \\
\hline 2 & 0.5 & 116066 & 3200 & 0.1 & $\$ 50$ & 0.25 & $\$ 15$ & $\$ 9000$ & $7.5 \%$ & 0.2 & $\$ 18$ & $\$ 18$ \\
\hline 3 & 0.5 & 120000 & 3400 & 0.1 & $\$ 60$ & 0.25 & $\$ 20$ & $\$ 9500$ & $12.5 \%$ & 0.2 & $\$ 20$ & $\$ 20$ \\
\hline 4 & 0.5 & 124068 & 3600 & 0.1 & $\$ 70$ & 0.25 & $\$ 25$ & $\$ 10000$ & $17.5 \%$ & 0.2 & $\$ 22$ & $\$ 22$ \\
\hline 5 & 0.5 & 128276 & 3800 & 0.1 & $\$ 80$ & 0.25 & $\$ 30$ & $\$ 10500$ & $22.5 \%$ & 0.2 & $\$ 24$ & $\$ 24$ \\
\hline
\end{tabular}

\section{Table 1}

The parameters' values assumed in stage one

\begin{tabular}{cccccccc}
\hline$\pi_{0}$ & $\gamma$ & $P_{1,0}$ & $x_{0}$ & $C_{0}$ & $\mathrm{i}_{0}$ & \\
0.4 & 0.5 & 120000 & $2.5 \%$ & $\$ 40$ & 0.2 & $h_{1,0}$ \\
\hline$\beta_{2,0}$ & $\delta$ & $\beta_{1,0}$ & $\lambda_{0}$ & $C_{\mathrm{S}, 0}$ & $K_{0}$ & $\$ 8$ \\
0.4 & 0.5 & -0.7 & 18218 & $\$ 10$ & $\$ 8500$ & $h_{4,0}$ \\
\hline
\end{tabular}

Table 2

The parameters' values assumed in in stage two 
Applying Eqs. (27) and (24), we gain $T_{\mathrm{Z}}^{*}=0.5516$ years and $E\left[T C U\left(T_{\mathrm{Z}}^{*}\right)\right]=\$ 2,516,667$ for our proposed multiproduct fabrication problem featuring postponement, external suppliers, overtime, and scrap. Figure 4 demonstrates the convexity of $E\left[T C U\left(T_{\mathrm{Z}}\right)\right]$ relating to $T_{\mathrm{Z}}$. It discovers that $E\left[T C U\left(T_{\mathrm{Z}}\right)\right]$ surges both sides as $T_{\mathrm{Z}}$ deviates from the optimal $T_{\mathrm{Z}}$ *

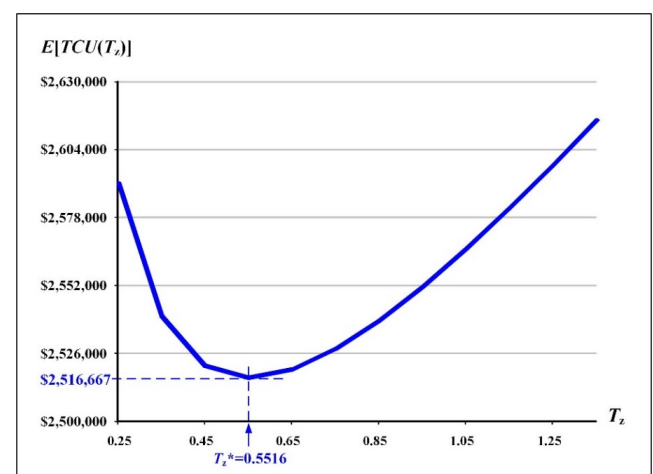

Fig. 4. The convexity of $E\left[T C U\left(T_{\mathrm{Z}}\right)\right]$ relating to $\mathrm{T}_{\mathrm{Z}}$

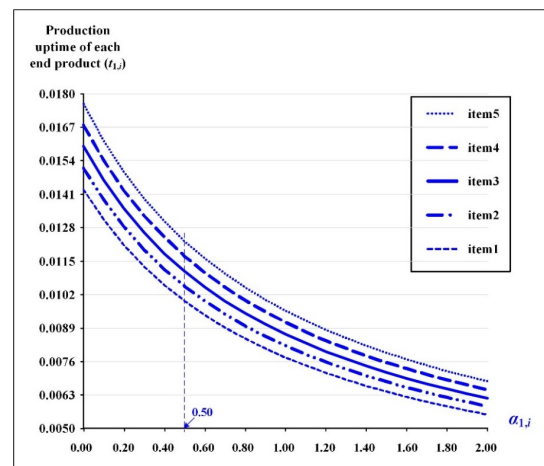

Fig. 5. Changes of each end-product's uptime $t_{1, \mathrm{i}}$ relating to $\alpha_{1, i}$

\subsection{Individual impact of overtime and external supplier on the problem}

With our proposed model's help, we can reveal diverse crucial system characteristics such as the impact of the overtime for fabricating end products and the external supply of the common parts on the problem. For instance, Fig. 5 demonstrates the analytical results from variations in $\alpha_{1, i}$ on each end-product's uptime $t_{1, i}$. It discloses that as $\alpha_{1, i}$ surges, end-products' uptimes knowingly declines. Fig. 6 illustrates the impact of the overtime for producing end products on utilization. It discovers that when the overtime increases the end products' output rate by $50 \%$, the machine utilization declines by $20.7 \%$ (i.e., it decreases from 0.2434 to 0.1930 , see Table C-1 in Appendix C).

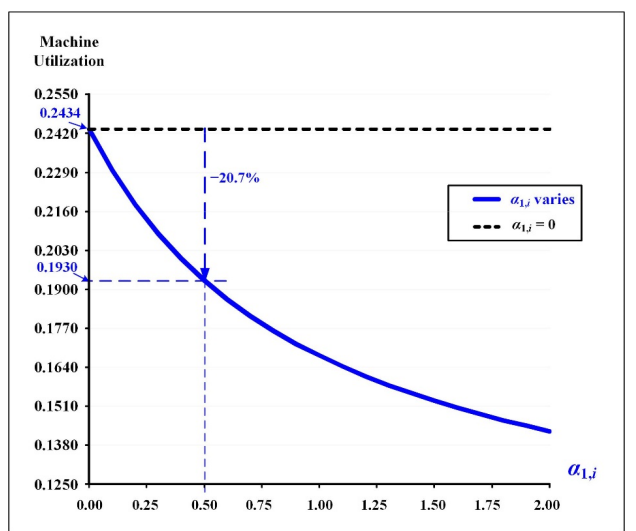

Fig. 6. The impact of the overtime for fabricating end products on machine utilization

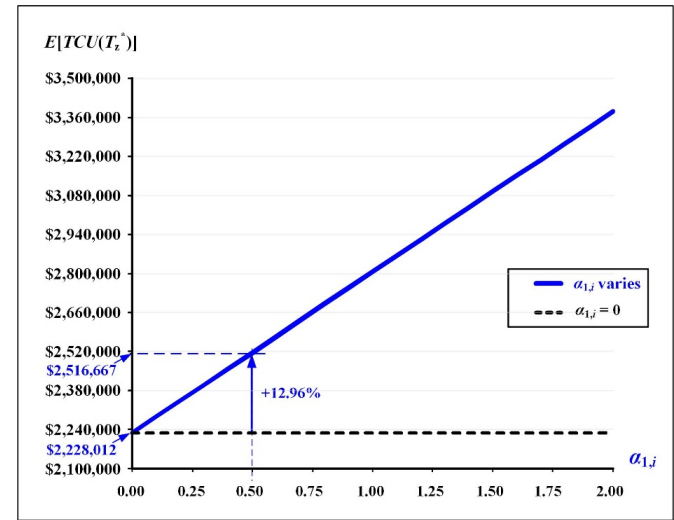

Fig. 7. Changes in $E\left[T C U\left(T_{Z}^{*}\right)\right]$ relating to $\alpha_{1, i}$

Fig. 7 illustrates that by reduction $20.7 \%$ of machine utilization, the proposed system pays the price of $12.96 \%$ in $E\left[T C U\left(T_{\mathrm{Z}}^{*}\right)\right]$ increase, i.e., $E\left[T C U\left(T_{\mathrm{Z}}^{*}\right)\right]$ increases from $\$ 2,228,012$ to $\$ 2,516,667$ (see Table C-1). Fig. 8 shows the analytical outcomes of the common parts' outsourcing portion $\pi_{0}$ on facility utilization. It exposes that when external providers supply $40 \%$ common parts, the system's utilization decreases from 0.2545 to 0.1930 or a decline of $24.2 \%$ (see Table C-2, Appendix C).

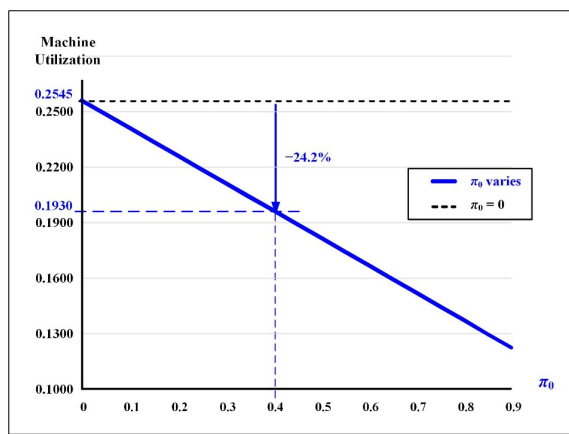

Fig. 8. Effect of the outsourcing portion $\pi_{0}$ on utilization

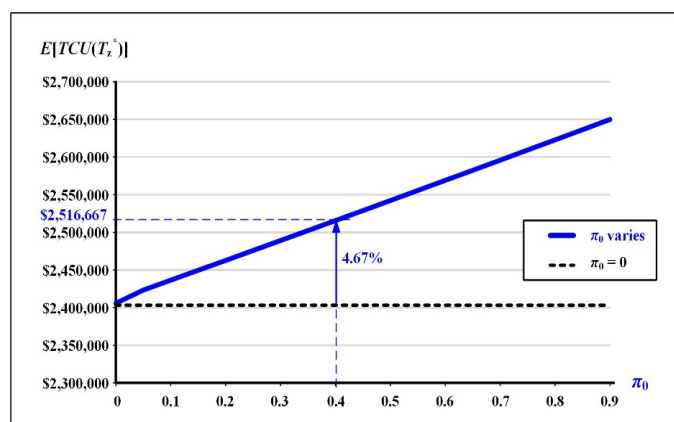

Fig. 9. Changes in $E\left[T C U\left(T_{\mathrm{Z}}^{*}\right)\right]$ concerning outsourcing percentage 
Fig. 9 exhibits that by reducing $24.2 \%$ of machine utilization, the proposed system pays a price of $4.67 \%$ in $E\left[T C U\left(T_{Z}^{*}\right)\right]$ increase, i.e., $E\left[T C U\left(T_{Z}^{*}\right)\right]$ rises from $\$ \$ 2,404,296$ to $\$ 2,516,667$ (see Table C-2 in Appendix C).

\subsection{Combined impact of overtime and outsourcing policies on the problem}

Fig. 10 explicitly studies the individual/combined influence of and $\pi_{0}$ and $\alpha_{1, i}$ on $E\left[T C U\left(T_{\mathrm{Z}}{ }^{*}\right)\right]$. According to this study's parameter assumptions, the analytical outcome indicates it is more economical to subcontract $40 \%$ common parts and gradually increase the overtime factor. Once $\alpha_{1, i}$ reaches 0.5 and $\pi_{0}$ remains at 0.4 , to further decrease utilization, the economical way is to stop increasing $\alpha_{1, i}$ (i.e., let overtime factor remain at 0.5 ) and only increase $\pi_{0}$. Our model is capable of performing the investigation for any given variable assumptions and exposes crucial information to facilitate managerial decision-making. For instance, $\pi_{0}=0.5$ is justified as a better starting value than $\pi_{0}=0.4$, if the managers are looking for a more economical $\pi_{0}$-value to cut down the utilization.

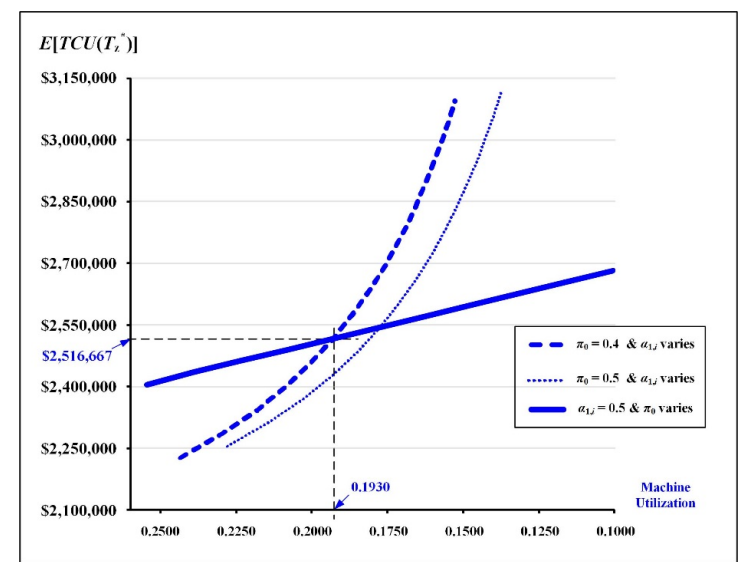

Fig. 10. The combined/individual influence of $\alpha_{1, i}$ and $\pi_{0}$ on $E\left[T C U\left(T_{\mathrm{Z}}^{*}\right)\right]$

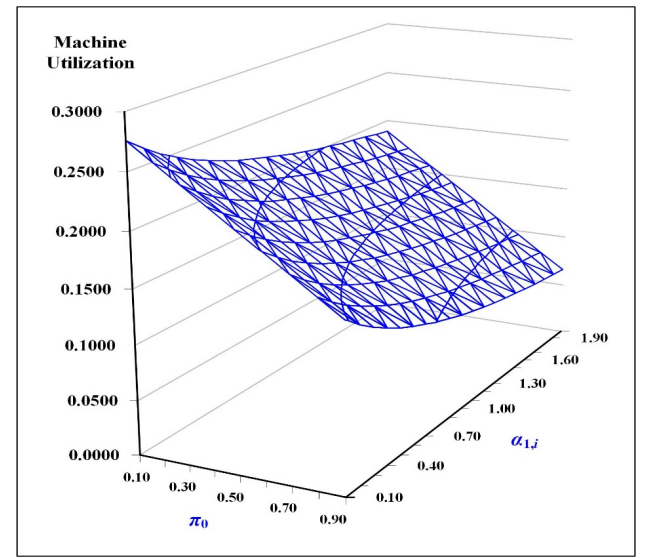

Fig. 11. Collective impact of $\alpha_{1, i}$ and $\pi_{0}$ on machine utilization

The collective effect of $\alpha_{1, i}$ and $\pi_{0}$ on utilization are investigated and demonstrated in Fig. 11. It shows as $\alpha_{1, i}$ surges, the utilization considerably declines; as $\pi_{0}$ increases, the utilization harshly drops. Fig. 12 illustrates the combined influence of $\pi_{0}$ and $\alpha_{1, i}$ on $E\left[T C U\left(T_{Z}^{*}\right)\right]$. It noticeably reveals as both $\pi_{0}$ and $\alpha_{1, i}$ go up, $E\left[T C U\left(T_{Z}^{*}\right)\right]$ rises considerably. It further exposes that $\alpha_{1, i}$ has more impact than $\pi_{0}$ on $E\left[T C U\left(T_{\mathrm{Z}}^{*}\right)\right]$ increase.

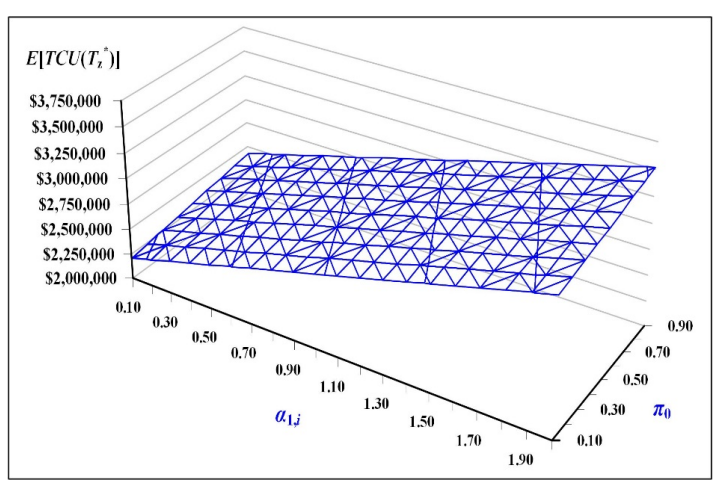

Fig. 12. Combined effect of $\alpha_{1, \mathrm{i}}$ and $\pi_{0}$ on $E\left[T C U\left(T_{\mathrm{Z}}^{*}\right)\right]$

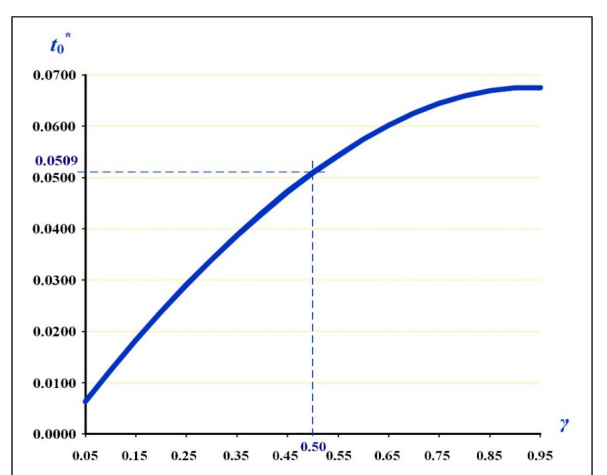

Fig. 13. Common part's uptime $t_{0}{ }^{*}$ relating to $\gamma$

\subsection{Effect of common part's completion rate and quality cost on the problem}

Fig. 13 displays the impact of $\gamma$ on the optimal uptime $t_{0}{ }^{*}$. It discovers as $\gamma$ increases, more manufacturing uptime $t_{0}{ }^{*}$ is required. As we assume $\gamma=0.5, t_{0}{ }^{*}$ is 0.0509 years (see Table C-2 in Appendix C). It also shows that at $\gamma=0.5$, by subcontracting $40 \%$ common parts, $t_{0}{ }^{*}$ drops from 0.0815 to 0.0509 or a drop of $37.55 \%$. Fig. 14 depicts the analytical results of $T_{\mathrm{Z}}{ }^{*}$ changes concerning the nonlinear and linear relationships between $\delta$ and $\gamma$. First, it verifies that in our example, when $\gamma=0.50, T_{Z}^{*}$ is 0.5516 years. It explicitly exposes crucial information of $T_{Z} *$ difference concerning two separate examples of nonlinear relationships between $\gamma$ and $\delta$. Fig. 15 depicts the detailed investigative results of cost contributors to $E\left[T C U\left(T_{\mathrm{Z}}{ }^{*}\right)\right]$. It indicates total quality costs (due to scraps) add up to $5.63 \%$ (i.e., $0.27 \%$ for fabricating the common parts and $5.36 \%$ in producing end products; for details, see Tables C-1 and C-2). The overtime and outsourcing relevant costs contribute $11.51 \%$ and $16.40 \%$ of $E\left[T C U\left(T_{\mathrm{Z}}{ }^{*}\right)\right]$. The variable cost (in-house) for end products and common parts contribute $44.77 \%$ and $17.65 \%$. Fig. 16 
demonstrates the behavior of cost contributors to $E\left[T C U\left(T_{\mathrm{Z}}^{*}\right)\right]$ relating to the average scrap rate $\bar{x}$. It discloses as $\bar{x}$ increases, the scrap related cost rises noticeably; other cost contributors slightly change.

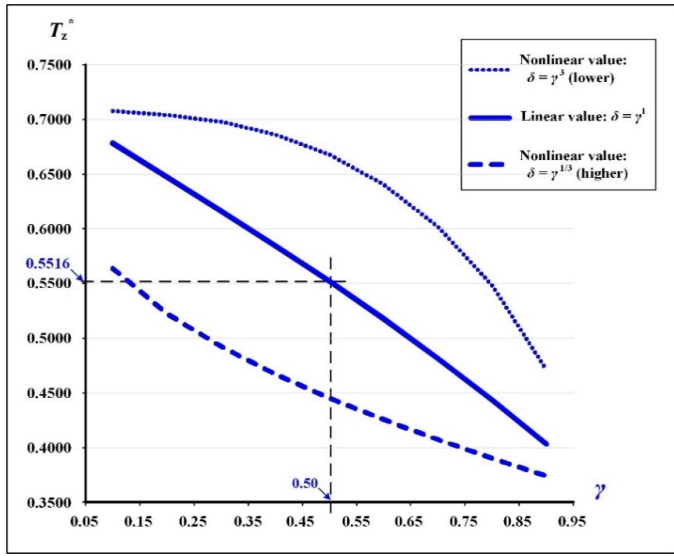

Fig. 14. The changes of $\mathrm{T}_{\mathrm{Z}} *$ relating to the nonlinear/linear relationships between $\delta$ and $\gamma$

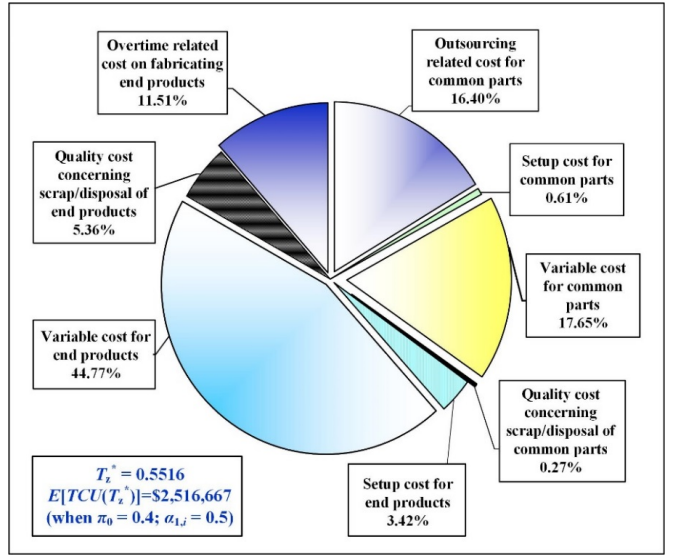

Fig. 15. Contributors to $E\left[T C U\left(T_{\mathrm{Z}}^{*}\right)\right]$

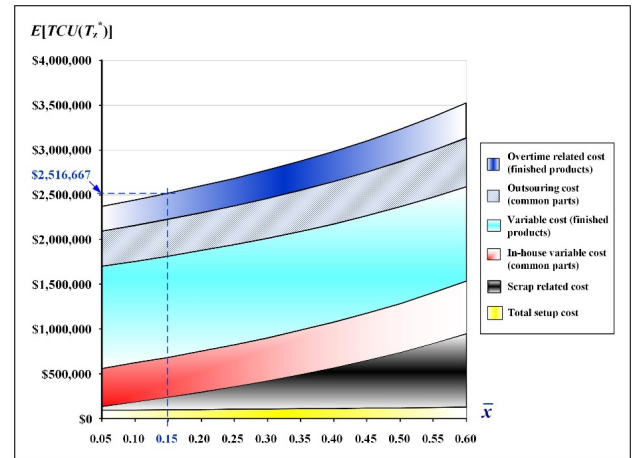

Fig. 16. The behavior of cost contributors to $E\left[T C U\left(T^{*}\right)\right]$ concerning $\bar{x}$

\section{Conclusions}

This work built a two-stage postponement model to investigate a multiproduct fabrication problem featuring products' commonality, scrap, external supplier, and overtime. It aimed to help manufacturing firms smoothen their fabrication planning and operations so that they could effectively meet today's client needs of various types of quality merchandise under the constraints of short order lead-time and limited in-house capacity. Section two, problem formulation, mathematical derivation, and differential calculus, helped us analyze and optimize the problem. Section three, a simulated numerical illustration, helped us validate the research result's applicability and demonstrate our model's capability to expose the crucial managerial insights and facilitate fabrication-relevant decision-making. These included:

(1) Total cost function's convexity and cost-minimized rotation cycle decision (refer to Fig. 4);

(2) Individual impact of overtime and external supplier on the problem (see Fig. 5 to Fig. 9);

(3) Combine impact of overtime and outsourcing strategies on the problem (refer to Figures 10 to 12);

(4) Common part's completion rate and quality cost effect on the problem (see Fig. 13 to Fig. 16).

An interesting and worthwhile topic for future work is combining a multi-delivery strategy for this multiproduct fabrication problem.

\section{Funding}

The researchers appreciate Ministry of Science and Technology of Taiwan for supporting this project (\#: MOST 109-2221E-324-015). 
Appendix A

\section{Nomenclature}

$T_{\mathrm{Z}} \quad=$ rotation cycle length,

$t_{1,0}=$ common parts' uptime,

$t_{2,0}=$ common parts' depletion time,

$H_{2,0}=$ level of common parts upon receipt of outsourced items,

$H_{1,0}=$ common part's inventory status when uptime ends,

$H_{i}=$ common part's inventory status when uptime of product $i$ completes,

$\lambda_{0}=$ common part's annual demand,

$Q_{0} \quad=$ common part's lot-size in stage 1 ,

$K_{0} \quad=$ common part's setup expense,

$P_{1,0}=$ common part's annual fabricating rate,

$x_{0}=$ common part's random scrap rate,

$d_{1,0}=$ fabricating rate of scrapped common parts, so, $d_{1,0}=x_{0} P_{1,0}$,

$C_{0}=$ common part's unit cost (in-house),

$\pi_{0}=$ common parts' outsourcing proportion per batch,

$K_{\pi 0} \quad=$ outsourcing's setup expense,

$\beta_{1,0}=$ the relating factor between $K_{0}$ and $K_{\pi 0}$,

$C_{\pi 0}=$ outsourcing common part's unit cost,

$\beta_{2,0}=$ the relating factor between $C_{0}$ and $C_{\pi 0}$,

$h_{1,0}=$ common part's unit holding cost,

$h_{4,0}=$ unit holding cost for safety common part,

$i_{0}=$ the relating factor between holding and unit costs (i.e., $h_{1,0}=C_{0} i_{0}$ ),

$C_{\mathrm{S}, 0}=$ disposal expense per scrapped common part,

$t_{0}{ }^{*}=$ common parts' optimal uptime,

$\gamma \quad=$ common part's completion rate compared to the finished product,

$S_{0} \quad=$ common part's setup time,

$I(t)_{i} \quad=$ stock level at time $t$ (for $\left.i=0,1,2, \ldots, L\right)$,

$t_{1, i} \quad=$ uptime for end product $i$,

$t_{2, i}=$ depleting time for end product $i$,

$H_{1, i} \quad=$ stock level of end product $i$ at the completion of its uptime,

$\lambda_{i} \quad=$ annual demand of end product $i$,

$Q_{i} \quad=$ batch size for end product $i$,

$K_{i} \quad=$ setup cost of end product $i$,

$P_{1, i} \quad=$ abricating rate of end product $i$ per year,

$P_{\mathrm{T} 1, i}=$ overtime output rate of end product $i$ per year,

$\alpha_{1, i}=$ the relating factor between $P_{1, i}$ and $P_{\mathrm{T} 1, i}$,

$K_{\mathrm{T}, i}=$ overtime setup cost of end product $i$,

$\alpha_{2, i}=$ the relating factor between and $K_{i}$ and $K_{\mathrm{T}, i}$,

$C_{i} \quad=$ ordinary unit cost of end product $i$,

$C_{\mathrm{T}, i}=$ overtime unit cost of end product $i$,

$\alpha_{3, i}=$ the relating factor between $C_{i}$ and $C_{\mathrm{T}, i}$,

$h_{1, i}=$ unit holding cost of end product $i$,

$h_{4, i}=$ unit holding cost of safety end product $i$,

$x_{i} \quad=$ random scrap rate of end product $i$,

$d_{\mathrm{T} 1, i}=$ fabricating rate of scrapped end product $i$ (where $d_{\mathrm{T} 1, i}=x_{i} P_{\mathrm{T} 1, i}$,

$C_{\mathrm{S}, i}=$ disposal expense per scrapped end product $i$,

$t_{i}^{*} \quad=$ the optimal total uptimes of end products,

$S_{i} \quad=$ setup time of end product $i$,

$T C\left(T_{\mathrm{Z}}\right)=$ total fabrication-inventory expense per cycle,

$E\left[T_{\mathrm{Z}}\right]=$ the expected rotation cycle time,

$E\left[T C\left(T_{\mathrm{Z}}\right)\right]=$ the expected total fabrication-inventory expense per cycle, $E\left[T C U\left(T_{\mathrm{Z}}\right)\right]=$ the expected total fabrication-inventory expense per unit time. 
Appendix B

Table B-1

The parameters' values assumed for a single-stage scheme of the same problem

\begin{tabular}{cccccccccc}
\hline Product $i$ & $x_{i}$ & $\lambda_{i}$ & $C_{i}$ & $i$ & $h_{1, i}$ & $C_{\mathrm{S}, i}$ & $P_{1, i}$ & $h_{4, i}$ & $K_{i}$ \\
\hline 1 & $5 \%$ & 3000 & $\$ 80$ & 0.2 & $\$ 16$ & $\$ 20$ & 58000 & $\$ 16$ & $\$ 17000$ \\
2 & $10 \%$ & 3200 & $\$ 90$ & 0.2 & $\$ 18$ & $\$ 25$ & 59000 & $\$ 18$ & $\$ 17500$ \\
3 & $15 \%$ & 3400 & $\$ 100$ & 0.2 & $\$ 20$ & $\$ 30$ & 60000 & $\$ 20$ & $\$ 18000$ \\
4 & $20 \%$ & 3600 & $\$ 110$ & 0.2 & $\$ 22$ & $\$ 35$ & 61000 & $\$ 22$ & $\$ 18500$ \\
5 & $25 \%$ & 3800 & $\$ 120$ & 0.2 & $\$ 24$ & $\$ 40$ & 62000 & $\$ 24$ & $\$ 19000$ \\
\hline
\end{tabular}

Appendix C

Table C-1

The influence of variations in overtime factor $\alpha_{1,0}$ on different system parameters

\begin{tabular}{|c|c|c|c|c|c|c|c|c|c|c|c|c|c|}
\hline$\alpha_{1,0}$ & $\alpha_{3,0}$ & $T_{\mathrm{Z}}^{*}$ & $\begin{array}{c}\mathrm{E}\left[T C U\left(T_{\mathrm{Z}}^{*}\right)\right] \\
(\mathrm{A})\end{array}$ & $\begin{array}{l}\text { (A) } \% \\
\text { increase }\end{array}$ & $\alpha_{2,0}$ & $t_{\mathrm{i}}^{*}$ & $\begin{array}{c}t_{\mathrm{i}}^{*} \\
\text { decline } \\
\%\end{array}$ & $\begin{array}{l}\text { Utiliza- } \\
\text { tion (B) }\end{array}$ & $\begin{array}{c}\text { (B) } \% \\
\text { decline }\end{array}$ & $\begin{array}{l}\text { Additional } \\
\text { cost due to } \\
\text { overtime } \\
\text { (C) }\end{array}$ & $\begin{array}{c}(\mathrm{C}) /(\mathrm{A}) \\
\%\end{array}$ & $\begin{array}{l}\text { Quality } \\
\text { cost of end } \\
\text { products } \\
\text { (D) }\end{array}$ & $\begin{array}{c}(\mathrm{D}) /(\mathrm{A}) \\
\%\end{array}$ \\
\hline 0.0 & 0.00 & 0.5278 & $\$ 2,228,012$ & - & 0.00 & 0.0798 & - & 0.2434 & - & $\$ 0$ & $0.00 \%$ & $\$ 113,916$ & $5.11 \%$ \\
\hline 0.1 & 0.05 & 0.5328 & $\$ 2,285,695$ & $2.59 \%$ & 0.02 & 0.0732 & $-8.23 \%$ & 0.2296 & $-5.7 \%$ & $\$ 57,986$ & $2.54 \%$ & $\$ 118,119$ & $5.17 \%$ \\
\hline 0.2 & 0.10 & 0.5377 & $\$ 2,343,412$ & $5.18 \%$ & 0.04 & 0.0677 & $-15.11 \%$ & 0.2182 & $-10.4 \%$ & $\$ 115,939$ & $4.95 \%$ & $\$ 122,322$ & $5.22 \%$ \\
\hline 0.3 & 0.15 & 0.5424 & $\$ 2,401,150$ & $7.77 \%$ & 0.06 & 0.0630 & $-20.95 \%$ & 0.2085 & $-14.3 \%$ & $\$ 173,862$ & $7.24 \%$ & $\$ 126,524$ & $5.27 \%$ \\
\hline 0.4 & 0.20 & 0.5471 & $\$ 2,458,904$ & $10.36 \%$ & 0.08 & 0.0590 & $-25.97 \%$ & 0.2002 & $-17.7 \%$ & $\$ 231,757$ & $9.43 \%$ & $\$ 130,727$ & $5.32 \%$ \\
\hline 0.5 & 0.25 & 0.5516 & $\$ 2,516,667$ & $12.96 \%$ & 0.10 & 0.0556 & $-30.32 \%$ & 0.1930 & $-20.7 \%$ & $\$ 289,624$ & $11.51 \%$ & $\$ 134,929$ & $5.36 \%$ \\
\hline 0.6 & 0.30 & 0.5561 & $\$ 2,574,437$ & $15.55 \%$ & 0.12 & 0.0525 & $-34.15 \%$ & 0.1867 & $-23.3 \%$ & $\$ 347,466$ & $13.50 \%$ & $\$ 139,132$ & $5.40 \%$ \\
\hline 0.7 & 0.35 & 0.5605 & $\$ 2,632,208$ & $18.14 \%$ & 0.14 & 0.0498 & $-37.53 \%$ & 0.1811 & $-25.6 \%$ & $\$ 405,282$ & $15.40 \%$ & $\$ 143,335$ & $5.45 \%$ \\
\hline 0.8 & 0.40 & 0.5649 & $\$ 2,689,981$ & $20.73 \%$ & 0.16 & 0.0474 & $-40.54 \%$ & 0.1762 & $-27.6 \%$ & $\$ 463,075$ & $17.21 \%$ & $\$ 147,537$ & $5.48 \%$ \\
\hline 0.9 & 0.45 & 0.5692 & $\$ 2,747,752$ & $23.33 \%$ & 0.18 & 0.0453 & $-43.24 \%$ & 0.1718 & $-29.4 \%$ & $\$ 520,845$ & $18.96 \%$ & $\$ 151,740$ & $5.52 \%$ \\
\hline 1.0 & 0.50 & 0.5734 & $\$ 2,805,521$ & $25.92 \%$ & 0.20 & 0.0433 & $-45.68 \%$ & 0.1678 & $-31.1 \%$ & $\$ 578,593$ & $20.62 \%$ & $\$ 155,943$ & $5.56 \%$ \\
\hline 1.1 & 0.55 & 0.5776 & $\$ 2,863,286$ & $28.51 \%$ & 0.22 & 0.0416 & $-47.89 \%$ & 0.1642 & $-32.5 \%$ & $\$ 636,320$ & $22.22 \%$ & $\$ 160,145$ & $5.59 \%$ \\
\hline 1.2 & 0.60 & 0.5818 & $\$ 2,921,046$ & $31.11 \%$ & 0.24 & 0.0400 & $-49.90 \%$ & 0.1609 & $-33.9 \%$ & $\$ 694,026$ & $23.76 \%$ & $\$ 164,348$ & $5.63 \%$ \\
\hline 1.3 & 0.65 & 0.5859 & $\$ 2,978,802$ & $33.70 \%$ & 0.26 & 0.0385 & $-51.74 \%$ & 0.1579 & $-35.1 \%$ & $\$ 751,712$ & $25.24 \%$ & $\$ 168,550$ & $5.66 \%$ \\
\hline 1.4 & 0.70 & 0.5900 & $\$ 3,036,551$ & $36.29 \%$ & 0.28 & 0.0371 & $-53.42 \%$ & 0.1552 & $-36.2 \%$ & $\$ 809,380$ & $26.65 \%$ & $\$ 172,753$ & $5.69 \%$ \\
\hline 1.5 & 0.75 & 0.5940 & $\$ 3,094,295$ & $38.88 \%$ & 0.30 & 0.0359 & $-54.98 \%$ & 0.1527 & $-37.3 \%$ & $\$ 867,028$ & $28.02 \%$ & $\$ 176,956$ & $5.72 \%$ \\
\hline 1.6 & 0.80 & 0.5980 & $\$ 3,152,033$ & $41.47 \%$ & 0.32 & 0.0348 & $-56.42 \%$ & 0.1504 & $-38.2 \%$ & $\$ 924,658$ & $29.34 \%$ & $\$ 181,158$ & $5.75 \%$ \\
\hline 1.7 & 0.85 & 0.6020 & $\$ 3,209,763$ & $44.06 \%$ & 0.34 & 0.0337 & $-57.76 \%$ & 0.1482 & $-39.1 \%$ & $\$ 982,271$ & $30.60 \%$ & $\$ 185,361$ & $5.77 \%$ \\
\hline 1.8 & 0.90 & 0.6060 & $\$ 3,267,487$ & $46.65 \%$ & 0.36 & 0.0327 & $-59.00 \%$ & 0.1462 & $-39.9 \%$ & $\$ 1,039,867$ & $31.82 \%$ & $\$ 189,564$ & $5.80 \%$ \\
\hline 1.9 & 0.95 & 0.6099 & $\$ 3,325,205$ & $49.25 \%$ & 0.38 & 0.0318 & $-60.16 \%$ & 0.1443 & $-40.7 \%$ & $\$ 1,097,447$ & $33.00 \%$ & $\$ 193,766$ & $5.83 \%$ \\
\hline 2.0 & 1.00 & 0.6137 & $\$ 3,382,915$ & $51.84 \%$ & 0.40 & 0.0309 & $-61.24 \%$ & 0.1426 & $-41.4 \%$ & $\$ 1,155,010$ & $34.14 \%$ & $\$ 197,969$ & $5.85 \%$ \\
\hline
\end{tabular}

Table C-2

The influence of variations in outsourcing factor $\pi_{0}$ on different system parameters

\begin{tabular}{|c|c|c|c|c|c|c|c|c|c|c|c|}
\hline$\pi_{0}$ & $T_{\mathrm{Z}} *$ & $t_{0}$ * & $\begin{array}{c}t_{0} * \\
\text { decline } \\
\%\end{array}$ & $\begin{array}{l}\text { Machine } \\
\text { Utiliza- } \\
\text { tion (A) }\end{array}$ & $\begin{array}{c}\text { (A) } \\
\text { decline } \\
\%\end{array}$ & $\begin{array}{c}\mathrm{E}\left[T C U\left(T_{\mathrm{Z}}{ }^{*}\right)\right] \\
\text { (B) }\end{array}$ & $\begin{array}{c}(\mathrm{B}) \\
\text { increase } \\
\%\end{array}$ & $\begin{array}{l}\text { Additional } \\
\text { cost due to } \\
\text { outsourcing } \\
\text { (C) }\end{array}$ & $\begin{array}{c}(\mathrm{C}) /(\mathrm{B}) \\
\%\end{array}$ & $\begin{array}{l}\text { Quality } \\
\text { cost of } \\
\text { common } \\
\text { parts (D) }\end{array}$ & $\begin{array}{c}(\mathrm{D}) /(\mathrm{B}) \\
\%\end{array}$ \\
\hline 0.00 & 0.5303 & 0.0815 & - & 0.2545 & - & $\$ 2,404,296$ & - & $\$ 0$ & $0.00 \%$ & $\$ 11,530$ & $0.48 \%$ \\
\hline 0.05 & 0.5428 & 0.0793 & $-2.76 \%$ & 0.2468 & $-3.0 \%$ & $\$ 2,422,403$ & $0.75 \%$ & $\$ 55,708$ & $2.30 \%$ & $\$ 10,954$ & $0.45 \%$ \\
\hline 0.10 & 0.5443 & 0.0753 & $-7.63 \%$ & 0.2391 & $-6.1 \%$ & $\$ 2,435,781$ & $1.31 \%$ & $\$ 106,706$ & $4.38 \%$ & $\$ 10,377$ & $0.43 \%$ \\
\hline 0.15 & 0.5457 & 0.0713 & $-12.54 \%$ & 0.2314 & $-9.1 \%$ & $\$ 2,449,187$ & $1.87 \%$ & $\$ 157,704$ & $6.44 \%$ & $\$ 9,801$ & $0.40 \%$ \\
\hline 0.20 & 0.5470 & 0.0673 & $-17.48 \%$ & 0.2237 & $-12.1 \%$ & $\$ 2,462,623$ & $2.43 \%$ & $\$ 208,704$ & $8.47 \%$ & $\$ 9,224$ & $0.37 \%$ \\
\hline 0.25 & 0.5482 & 0.0632 & $-22.46 \%$ & 0.2160 & $-15.1 \%$ & $\$ 2,476,089$ & $2.99 \%$ & $\$ 259,703$ & $10.49 \%$ & $\$ 8,648$ & $0.35 \%$ \\
\hline 0.30 & 0.5494 & 0.0591 & $-27.47 \%$ & 0.2084 & $-18.1 \%$ & $\$ 2,489,585$ & $3.55 \%$ & $\$ 310,704$ & $12.48 \%$ & $\$ 8,071$ & $0.32 \%$ \\
\hline 0.35 & 0.5506 & 0.0550 & $-32.52 \%$ & 0.2007 & $-21.1 \%$ & $\$ 2,503,111$ & $4.11 \%$ & $\$ 361,704$ & $14.45 \%$ & $\$ 7,495$ & $0.30 \%$ \\
\hline 0.40 & 0.5516 & 0.0509 & $-37.55 \%$ & 0.1930 & $-24.2 \%$ & $\$ 2,516,667$ & $4.67 \%$ & $\$ 412,706$ & $16.40 \%$ & $\$ 6,918$ & $0.27 \%$ \\
\hline 0.45 & 0.5526 & 0.0467 & $-42.69 \%$ & 0.1853 & $-27.2 \%$ & $\$ 2,530,254$ & $5.24 \%$ & $\$ 463,708$ & $18.33 \%$ & $\$ 6,342$ & $0.25 \%$ \\
\hline 0.50 & 0.5535 & 0.0425 & $-47.81 \%$ & 0.1776 & $-30.2 \%$ & $\$ 2,543,872$ & $5.81 \%$ & $\$ 514,711$ & $20.23 \%$ & $\$ 5,765$ & $0.23 \%$ \\
\hline 0.55 & 0.5544 & 0.0384 & $-52.96 \%$ & 0.1699 & $-33.2 \%$ & $\$ 2,557,520$ & $6.37 \%$ & $\$ 565,714$ & $22.12 \%$ & $\$ 5,189$ & $0.20 \%$ \\
\hline 0.60 & 0.5552 & 0.0341 & $-58.13 \%$ & 0.1622 & $-36.3 \%$ & $\$ 2,571,199$ & $6.94 \%$ & $\$ 616,718$ & $23.99 \%$ & $\$ 4,612$ & $0.18 \%$ \\
\hline 0.65 & 0.5559 & 0.0299 & $-63.31 \%$ & 0.1545 & $-39.3 \%$ & $\$ 2,584,909$ & $7.51 \%$ & $\$ 667,723$ & $25.83 \%$ & $\$ 4,036$ & $0.16 \%$ \\
\hline 0.70 & 0.5565 & 0.0257 & $-68.52 \%$ & 0.1469 & $-42.3 \%$ & $\$ 2,598,651$ & $8.08 \%$ & $\$ 718,728$ & $27.66 \%$ & $\$ 3,459$ & $0.13 \%$ \\
\hline 0.75 & 0.5570 & 0.0214 & $-73.74 \%$ & 0.1392 & $-45.3 \%$ & $\$ 2,612,424$ & $8.66 \%$ & $\$ 769,734$ & $29.46 \%$ & $\$ 2,883$ & $0.11 \%$ \\
\hline 0.80 & 0.5575 & 0.0171 & $-78.97 \%$ & 0.1315 & $-48.3 \%$ & $\$ 2,626,228$ & $9.23 \%$ & $\$ 820,740$ & $31.25 \%$ & $\$ 2,306$ & $0.09 \%$ \\
\hline 0.85 & 0.5579 & 0.0129 & $-84.22 \%$ & 0.1238 & $-51.4 \%$ & $\$ 2,640,064$ & $9.81 \%$ & $\$ 871,747$ & $33.02 \%$ & $\$ 1,730$ & $0.07 \%$ \\
\hline 0.90 & 0.5582 & 0.0086 & $-89.47 \%$ & 0.1161 & $-54.4 \%$ & $\$ 2,653,931$ & $10.38 \%$ & $\$ 922,755$ & $34.77 \%$ & $\$ 1,153$ & $0.04 \%$ \\
\hline 0.95 & 0.5585 & 0.0043 & $-94.73 \%$ & 0.1084 & $-57.4 \%$ & $\$ 2,667,830$ & $10.96 \%$ & $\$ 973,764$ & $36.50 \%$ & $\$ 577$ & $0.02 \%$ \\
\hline 1.00 & 0.5198 & 0.0000 & $-100.0 \%$ & 0.1007 & $-60.4 \%$ & $\$ 2,665,996$ & $10.88 \%$ & $\$ 1,025,114$ & $38.45 \%$ & $\$ 0$ & $0.00 \%$ \\
\hline
\end{tabular}




\section{References}

Abdel-Aal, M.A.M. (2019). A robust capacitated lot sizing problem with setup times and overtime decisions with backordering allowed under demand uncertainty. IFAC-Papers OnLine, 52, 589-594.

Abdul Halim, M., Paul, A., Mahmoud, M., Alshahrani, B., Alazzawi, A.Y.M., \& Ismail, G.M. (2021). An overtime production inventory model for deteriorating items with nonlinear price and stock dependent demand. Alexandria Engineering Journal, 60(3), 2779-2786.

Alves, A.C., Ferreira, A.C., Maia, L.C., Leão, C.P., \& Carneiro, P. (2019). A symbiotic relationship between Lean Production and Ergonomics: Insights from Industrial Engineering final year projects. International Journal of Industrial Engineering and Management, 10(4), 243-256.

Aviv, Y., \& Federgruen, A. (2001). Design for postponement: A comprehensive characterization of its benefits under unknown demand distributions. Operations Research, 49(4), 578-598.

Belogusev, V., \& Egorov, A. (2019). Development of a method and instruments to assess the build quality and the technical condition of an electric gear actuator for an electromechanical orthosis of a lower limb exoskeleton. Journal of Applied Engineering Science, 17(3), 386-394.

Boctor, F.F., \& Poulin, P. (2007). Heuristics for the N-product, M-stage, economic lot sizing and scheduling problem with dynamic demand. International Journal of Production Research, 43(13), 2809-2828.

Cerdá, J., Cafaro, V.G., \& Cafaro, D.C. (2020). Synchronizing operations in multiproduct batch facilities producing semifinished and final products. Industrial and Engineering Chemistry Research, 59(29), 13113-13131.

Ceryan, O., Duenyas, I., \& Koren, Y. (2012). Optimal control of an assembly system with demand for the end-product and intermediate components. IIE Transactions, 44(5), 386-403.

Chiu, S.W., Zhao, Z-Y., Chiu, T., \& Chiu, Y-S.P. (2020). Combining the delayed differentiation policy and common parts' partial outsourcing strategy into a multi-item fpr-based system. Journal of Applied Engineering Science, 18(2), 273-280.

Chiu, S.W., Chiu, T., Chiu, Y-S.P., \& Lin, H-D. (2021). Economic manufacturing quantity model with machine failure, overtime, and rework/disposal of nonconforming items. Management and Production Engineering Review, 12(1), 3-16.

Fontinha, R., Easton, S., \& Van Laar, D. (2019). Overtime and quality of working life in academics and nonacademics: The role of perceived work-life balance. International Journal of Stress Management, 26(2), 173-183.

Insinga, R.C., \& Werle, M.J. (2020). Linking Outsourcing to Business Strategy. Academy of Management Executive, 14(4), 58-70.

Kenne, J.P., Boukas, E.K., \& Gharbi, A. (2003). Control of production and corrective maintenance rates in a multiplemachine, multiple-product manufacturing system. Mathematical and Computer Modelling, 38(3-4), 351-365.

Keyvanshokooh, E., Shi, C., \& van Oyen, M.P. (2021). Online advance scheduling with overtime: A primal-dual approach. Manufacturing and Service Operations Management, 23(1), 246-266.

Kundu, A., Guchhait, P., Das, B., \& Maiti, M. (2019). A multi-item EPQ model with variable demand in an imperfect production process. Advances in Intelligent Systems and Computing, 699, 217-233.

Nogueira, T.H., Bettoni, A.B., Mendes, G.T.D.O., dos Santos, A.G., \& Ravetti, M.G. (2020). Problem on the integration between production and delivery with parallel batching machines of generic job sizes and processing times. Computers and Industrial Engineering, 146, Art. No. 106573

Pasupa, T., \& Suzuki, S. (2019). Impact of work-sharing on the performance of production line with heterogeneous workers. International Journal of Industrial Engineering and Management, 10(4), 284-302.

Pinto, L.F.R., Neto, G.C.O., Mummolo, G., Digiesi, S., Facchini, F., \& Centoamore, P. (2020). Cleaner production initiatives in a diesel engines factory. International Journal of Industrial Engineering and Management, 11(2), 73-80.

Salehi Amiri, S.A.H., Zahedi, A., Kazemi, M., Soroor, J., \& Hajiaghaei-Keshteli, M. (2020). Determination of the optimal sales level of perishable goods in a two-echelon supply chain network. Computers and Industrial Engineering, 139, Art. No. 106156

Sarkar, B., \& Moon, I. (2011). An EPQ model with inflation in an imperfect production system. Applied Mathematics and Computation, 217 (13), 6159-6167.

Sarkar, M., \& Chung, B.D. (2020). Flexible work-in-process production system in supply chain management under quality improvement. International Journal of Production Research, 58(13), 3821-3838

Sharma, G., \& Rai, R.N. (2021). Age based overhaul policy for multiple repairable systems with imperfect maintenance: case study of Aero engines. International Journal of Mathematical, Engineering and Management Sciences, 6(1), 193-206.

Soriano, J., Jalao, E.R., \& Martinez, I.A. (2020). Integrated employee scheduling with known employee demand, including breaks, overtime, and employee preferences. Journal of Industrial Engineering and Management, 13(3), 451-463.

Westphal, P., \& Sohal, A.S. (2013). Taxonomy of outsourcing decision models. Production Planning \& Control, 24(4-5), $347-358$

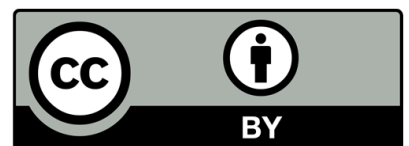

(C) 2022 by the authors; licensee Growing Science, Canada. This is an open access article distributed under the terms and conditions of the Creative Commons Attribution (CCBY) license (http://creativecommons.org/licenses/by/4.0/). 